\title{
Purification of Crude Phosphoric Acid and Leached Apatite by Solvent Extraction with CYANEX 923 in Kerosene
}

\author{
Ismail M. Ahmed ${ }^{1 *}$, Romany N. Ammanoeil², Ebtissam A. Saad ${ }^{2}$, Jacqueline A. Daoud ${ }^{1}$ \\ ${ }^{1}$ Hot Laboratories Centre, Atomic Energy Authority, Post Code 13759, Cairo, Egypt \\ 2 Faculty of Science, Ain Shams University, Post Code 1156, Cairo, Egypt \\ * Corresponding author, email: ismadwy@yahoo.ca
}

Received: 20 October 2017, Accepted: 21 February 2018, Published online: 20 March 2018

\begin{abstract}
CYANEX 923 (a mixture of four trialkylphosphine oxides) in kerosene has been used for the extraction of phosphoric acid. Different parameters affecting the extraction of phosphoric acid such as shaking time, temperature, phase ratio O/A, extractant and phosphoric acid concentration were separately investigated. The stoichiometry of the extracted species was found to be $\mathrm{H}_{3} \mathrm{PO} \mathrm{O}_{4} \cdot \mathrm{L}, \mathrm{where} L$ refers to CYANEX 923. The stripping of the extracted species was found to be efficient with water. The obtained results were used for the recovery of phosphoric acid from both the crude acid and the leached solution from digestion of apatite phosphate rock with hydrochloric acid. Expanded Perlite was found to be efficient for the adsorption of uranium from both crude acid and the leached apatite.
\end{abstract}

Keywords

Phosphoric acid, Purification, Solvent extraction, CYANEX 923, Apatite ore, Perlite

\section{Introduction}

Purification of acid is necessary for its use in foodstuffs, in animal feed additives, detergents, food products, toothpaste and fertilizers [1-3]. Solvent extraction technique has been widely used for purifying wet process phosphoric acid (WPA). A large number of organic solvents are reported for this purpose and some of them have been used in industrial operations, as alcohols, ethers, ketones and phosphoric esters which are effective extractants for phosphoric acid and have been frequently used [4-14]. Furthermore, it was found that co-existing mineral acids enhanced the extraction of phosphoric acid with several solvents. Several physicochemical treatment techniques based on precipitation [15-17], adsorption [18], ion exchange and reverse osmosis were also used [19-20]. Most of the above mentioned authors studied the extraction of relatively low phosphoric acid concentration, while the present work aims to study the potential use of CYANEX 923 for the extraction of concentrated phosphoric acid. The different parameters affecting the extraction process were investigated and the optimum conditions for extraction and stripping of phosphoric acid were deduced. Based on the obtained results, the extraction of phosphoric acid from crude wet process phosphoric acid and from a leach solution of apatite phosphate rock was carried out and the proposed processes are discussed and evaluated.

\section{Experimental}

\subsection{Chemicals and Reagents}

Most of the chemicals used are of analytical reagent grade (AR) and were used without further purification. Synthetic aqueous solutions were prepared by dissolving appropriate amounts of phosphoric acid $\left(85 \% \mathrm{H}_{3} \mathrm{PO}_{4}\right)$ or hydrochloric acid (min. 35\% $\mathrm{HCl}$ ) in bi-distilled water. The extractant CYANEX 923 is a mixture of four trialkyl-phosphine oxides, namely, dioctyl-hexylphosphine oxide $(\approx 42 \%)$, dihexyloctylphosphine oxide $(\approx 32 \%)$, trihexylphosphine oxide $(\approx 8 \%)$ and trioctylphosphine oxide $(\approx 14 \%)$. Its average molecular weight is taken as $348.0 \mathrm{~g} / \mathrm{mol}$ and was kindly supplied by Cytec, Canada and used as received. Kerosene is a product of Misr Petroleum Ltd., Egypt and was used as diluent. Expanded perlite, which consists mainly of silica and alumina of grain size $0-5 \mathrm{~mm}$, was kindly supplied by the Egyptian company for manufacturing perlite and vermiculite, Alexandria, Egypt. The composition of perlite is given in Table 1 . 
Table 1 The chemical composition of perlite.

\begin{tabular}{lclc}
\hline Constituent & $\%$ & Constituent & $\%$ \\
\hline $\mathrm{SiO}_{2}$ & 72.6 & $\mathrm{~K}_{2} \mathrm{O}$ & 8.1 \\
$\mathrm{Al}_{2} \mathrm{O}_{3}$ & 11.4 & $\mathrm{CaO}$ & 1.91 \\
$\mathrm{Na}_{2} \mathrm{O}$ & 2.3 & $\mathrm{TiO}_{2}$ & 0.25 \\
$\mathrm{MgO}$ & 0.19 & $\mathrm{MnO}$ & 0.11 \\
$\mathrm{P}_{2} \mathrm{O}_{5}$ & 0.36 & $\mathrm{Fe}_{2} \mathrm{O}_{3}$ & 1.78 \\
$\mathrm{SO}_{3}$ & 0.42 & Others & 0.58 \\
\hline
\end{tabular}

The apatite sample was collected from Abu Tartur plateau located in the western desert of Egypt. The chemical analysis of the phosphate rock of size fraction 150 micron through ASTM standard sieves is shown in Table 2.

\subsection{Procedures}

Preliminary experiments were carried out on pure phosphoric acid whereas the application studies were carried out using crude phosphoric acid obtained from the local market, Egypt, (containing $\mathrm{P}_{2} \mathrm{O}_{5}=56.5 \%, \mathrm{Fe}=3 \%$, $\mathrm{F}=0.95 \%$ and $\mathrm{U}(\mathrm{VI})=112 \mathrm{ppm})$. Fluoride ions were determined by ion selective electrode, the highly acidic solutions were adjusted to $\mathrm{pH}$ 5-6 before adding TISAB, (Total Ionic Strength Adjustment Buffer) [21] while iron and uranium content was determined using ICP-OES after a proper dilution. The crude acid was first purified from suspended matter using a sand filter column (with internal diameter $2.5 \mathrm{~cm}$; length $10 \mathrm{~cm}$ ) filled with sand of particle size 64 mesh to acquire the green acid. Fluoride ions were removed as sodium fluorosilicate by adding sodium chloride with stoichiometric ratio $200 \%$ for $30 \mathrm{~min}$. [17].

The phosphoric acid present in the aqueous phase was titrated with sodium hydroxide in the presence of bromocresol green as indicators [22]. Prior to the use of sodium hydroxide solution, it was calibrated with dried potassium hydrogen phthalate.

\subsubsection{Adsorption experiments}

The expanded perlite was used in the adsorption investigations that were carried out in the application experiments. The adsorption isotherm was obtained by varying the initial concentration of iron(III) and uranium(VI) ions in the solution. The amount of Fe(III) and U(VI) adsorbed per unit mass of adsorbent $\left(\mathrm{q}_{\mathrm{e}}\right)$ was calculated using the following equation,

$q_{e}=\frac{\left(C_{i}-C_{e}\right) \cdot V}{W}$
Table 2 The chemical composition of apatite ore.

\begin{tabular}{llll}
\hline Constituent & $\%$ & Constituent & $\%$ \\
\hline $\mathrm{P}_{2} \mathrm{O}_{5}$ & 30.1 & $\mathrm{~K}_{2} \mathrm{O}$ & 0.04 \\
$\mathrm{CaO}$ & 44.4 & $\mathrm{Fe}_{2} \mathrm{O}_{3}$ & 3.80 \\
$\mathrm{Na}_{2} \mathrm{O}$ & 0.28 & $\mathrm{~F}$ & 2.80 \\
$\mathrm{MgO}$ & 0.46 & $\mathrm{SO}_{3}$ & 1.50 \\
$\mathrm{Al}_{2} \mathrm{O}_{3}$ & 0.90 & L.I.O & 5.10 \\
$\mathrm{SiO}_{2}$ & 2.30 & & \\
\hline L.O.I. $=$ Loss on ignition & &
\end{tabular}

where $\mathrm{C}_{\mathrm{i}}$ and $\mathrm{C}_{\mathrm{e}}$ represent the initial and equilibrium concentrations in $\mathrm{mg} / \mathrm{L}$, respectively, $\mathrm{V}$ is the volume of the solution in litres (L), and $\mathrm{W}$ is the mass of the adsorbent in $\mathrm{g}$.

\subsubsection{Liquid-liquid Extraction}

Extraction procedures were carried out by shaking equal volumes of the organic solvent and the aqueous solution for $15 \mathrm{~min}$. at $25^{\circ} \mathrm{C}$. The phases were then separated by centrifugation and samples were taken from the aqueous phase for analysis. The experiments were carried out under thermostatic conditions at $25^{\circ} \mathrm{C}$.

The acid and metal ion concentration in the organic phase was calculated from the difference of their concentrations in the aqueous phase before and after extraction. The distribution ratio (D) was calculated as the ratio of the concentration of the acid or the metal ion in the organic phase to its concentration in the aqueous phase according to the relation:

$D=\frac{C_{o}-C}{C} \cdot \frac{V_{a q}}{V_{o r g}}$

The Extraction \% is calculated from the relation:

$\% E=\frac{100 D}{D+\frac{V_{o r g}}{V_{a q}}}$

where $\mathrm{C}_{\mathrm{o}}$ is the original concentration before extraction and $\mathrm{C}$ the final concentration after extraction in the aqueous phase, while $V_{a q}$ and $V_{o r g}$ are the volumes of the aqueous and organic phases, respectively.

In the leaching experiments, $25.0 \mathrm{~g}$ of the phosphate sample was stirred with $100 \mathrm{~mL}$ of $20 \% \mathrm{HCl}$ at $25^{\circ} \mathrm{C}$ at stirring rate $200 \mathrm{rpm}$ for $2 \mathrm{hrs}$. The samples were removed and filtered to remove the solid suspension. The concentration of $\mathrm{P}_{2} \mathrm{O}_{5}, \mathrm{U}, \mathrm{Fe}$ and $\mathrm{F}$ in the leach solutions was determined. 


\section{Results and discussion}

3.1 Extraction of phosphoric acid by Cyanex 923

\subsubsection{Effect of shaking time}

The effect of shaking time on the extraction of $7.0 \mathrm{M}$ $\mathrm{H}_{3} \mathrm{PO}_{4}$ by $1.18 \mathrm{M}$ CYANEX 923 at organic/aqueous, $\mathrm{O} / \mathrm{A}=2 / 1$ and $25^{\circ} \mathrm{C}$ was investigated from 1 to $120 \mathrm{~min}$. The results showed that the extraction equilibrium was reached within $15 \mathrm{~min}$, then the extraction decreased with further increase in the shaking time, Fig. 1. After the extraction of phosphoric acid reached equilibrium, the water in the aqueous phase causes back extraction of the loaded acid as the shaking time is prolonged, leading to a decrease in the extraction percent. Therefore, the shaking time was fixed at 15 minutes for all the experiments carried out in this work.

\subsubsection{Effect of extractant concentration}

The effect of CYANEX 923 concentration on the extraction of 7.0 $\mathrm{M} \mathrm{H}_{3} \mathrm{PO}_{4}$ was performed in the range $0.5-2.0 \mathrm{M}$. The plot drawn between $\log D$ and $\log$ [CYANEX 923] in Fig. 2 gave a straight line with slope value $\approx 1.2$, thus suggesting the involvement of one molecule of CYANEX 923 and one molecule of $\mathrm{H}_{3} \mathrm{PO}_{4}$ in the formation of the extracted species, Fig. 2.

\subsubsection{Effect of initial phosphoric acid concentration}

The effect of initial phosphoric acid concentration on the extraction process in the range from 1.0-11.0 $\mathrm{M}$ with 1.18 M CYANEX 923 at $\mathrm{O} / \mathrm{A}=2 / 1$ and $25{ }^{\circ} \mathrm{C}$ was investigated. The results show that the extraction increased with increasing phosphoric acid concentration up to $7.0 \mathrm{M}$ then became nearly constant, this can be referred to the reason that above $7 \mathrm{M} \mathrm{H}_{3} \mathrm{PO}_{4}$, due to saturation of the extractant with the acid that is agree with the results obtained in tri-n-butylphosphate (TBP) system [23].

\subsubsection{Effect of organic/aqueous $(\mathrm{O} / \mathrm{A})$ phase ratio}

The effect of $\mathrm{O} / \mathrm{A}$ phase ratio in the range from 1.0 to 5.0 on the extraction efficiency of $7.0 \mathrm{M} \mathrm{H}_{3} \mathrm{PO}_{4}$ by $1.18 \mathrm{M}$ CYANEX 923 is shown in Table 3. The data show that the extraction efficiency decreased as the aqueous phase volume increased due to the increase in the viscosity of the aqueous phase which therefore decreases the coefficient of mass transfer [7]. The ratio O/A which equals 2.0 was found to be suitable for the investigation from the economic point of view.

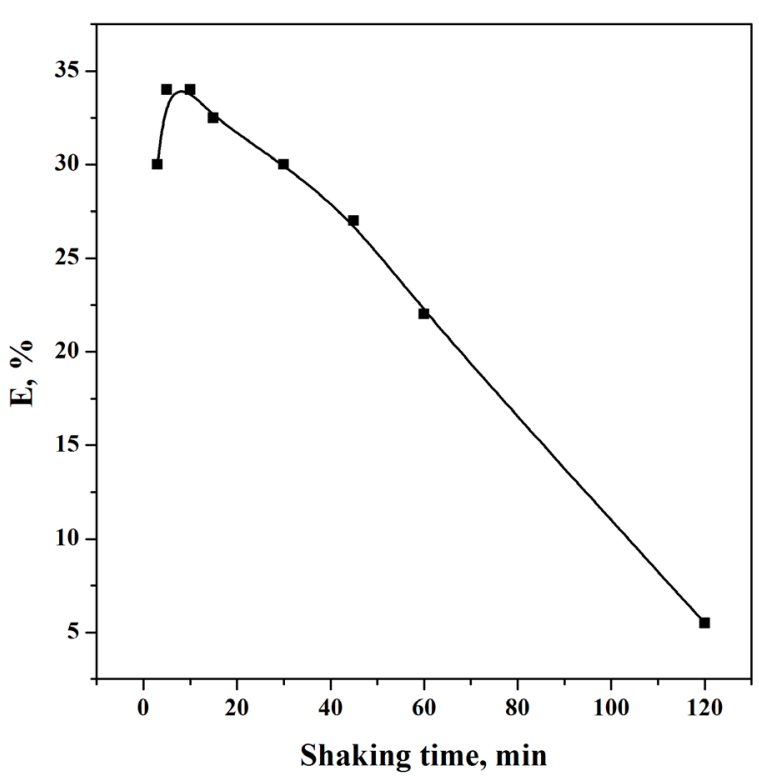

Fig. 1 Effect of shaking time on the extraction of $7 \mathrm{M} \mathrm{H}_{3} \mathrm{PO}_{4}$ by $1.18 \mathrm{M}$ CYANEX 923 in kerosene at phase ratio (O/A) 2:1.

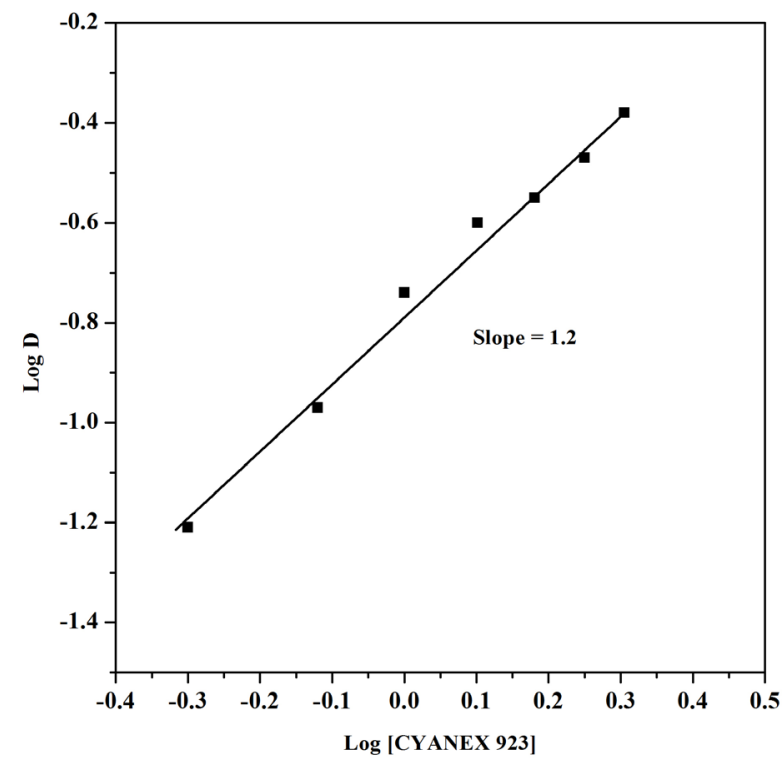

Fig. 2 Effect of CYANEX 923 concentration on the extraction of $7 \mathrm{M}$ $\mathrm{H}_{3} \mathrm{PO}_{4}$ at phase ratio (O/A) 2:1.

Table 3 Effect of phase ratio O/A on the extraction percent of $7.0 \mathrm{M}$ $\mathrm{H}_{3} \mathrm{PO}_{4}$ by $50 \%$ CYANEX 923 in kerosene

\begin{tabular}{ll}
\hline $\mathrm{O} / \mathrm{A}$ & $\mathrm{E}, \%$ \\
\hline 1 & 16 \\
2 & 34 \\
3 & 53 \\
4 & 68 \\
5 & 79 \\
\hline
\end{tabular}




\subsubsection{Effect of temperature}

The effect of temperature on the extraction of $7 \mathrm{M} \mathrm{H}_{3} \mathrm{PO}_{4}$ was performed in the range $15-40{ }^{\circ} \mathrm{C}$ using $1.18 \mathrm{M}$ CYANEX 923 in kerosene at phase ratio (O/A) 2:1. The data obtained show that the change in temperature had nearly no effect within the investigated temperature range. Based on the above experimental results, and considering that the predominant species of phosphoric acid at 7.0 $\mathrm{M}$ is the orthophosphoric acid, $\mathrm{H}_{3} \mathrm{PO}_{4}[8,24]$ the extraction reaction may be represented at equilibrium by:

$$
\mathrm{H}_{3} \mathrm{PO}_{4}+\mathrm{C} 923(\mathrm{org}) \rightleftharpoons \mathrm{H}_{3} \mathrm{PO}_{4} \mathrm{C} 923_{(\text {org })}
$$

And $K_{e x}=\frac{D}{[\overline{C 923]}}, M^{-1}$

The extraction equilibrium was calculated with respect to CYANEX 923 in the range $0.5-2.0 \mathrm{M}$ and was found to be $0.174 \pm 0.012 \mathrm{M}^{-1}$.

\subsection{Adsorption investigations}

The crude acid was passed over a sand filter to remove the suspended materials then was stirred with $10 \mathrm{~g} / \mathrm{L}$ activated carbon to remove the organic matter and some inorganic impurities. A green phosphoric acid containing $56.5 \% \mathrm{P}_{2} \mathrm{O}_{5}, 1.6 \% \mathrm{Fe}, 0.95 \% \mathrm{~F}$ and $112 \mathrm{ppm} \mathrm{U}$. It has to be mentioned that the activated carbon remove the humic substances that oppose the extraction process and minimize the concentration of iron from $3 \%$ to $1.6 \%$ [23].

The filtered solution was treated with $5.0 \mathrm{~g}$ of sodium chloride per liter of phosphoric acid for 3.0 hrs. at $25^{\circ} \mathrm{C}$ to eliminate the fluoride as sodium fluoro silicate, $\mathrm{Na}_{2} \mathrm{SiF}_{6}$ [17], according to the following equation:

$$
\mathrm{SiF}_{6}^{-2}+2 \mathrm{Na}^{+} \rightarrow \mathrm{Na}_{2} \mathrm{SiF}_{6}
$$

Expanded perlite was used in this investigation to study the effect of perlite of relatively high silica content as an economic sorbent for the removal of iron and uranium from phosphoric acid.

The sorption behavior of perlite is due to the silanol groups, $\mathrm{Si}-\mathrm{OH}$, which are formed by silicon atoms on the surface of perlite [25].

\subsubsection{Effect of adsorbent dose}

The effect of the adsorbent dose on the adsorption of wet process phosphoric acid containing $16 \times 10^{3} \mathrm{ppm} \mathrm{Fe}(\mathrm{III})$ and 112 ppm U(VI) was studied by using different doses of expanded perlite in the range $10-60 \mathrm{~g} / \mathrm{L}$ at $25^{\circ} \mathrm{C}$, while keeping the other parameters constant. Fig. 4 shows that the adsorption Fe(III) increased by increasing the adsorbent doses due to the increase of the surface area at higher doses of the adsorbent. The significant increase in the uptake was observed when the dose increased from 10 to $50 \mathrm{~g} / \mathrm{L}$, while further addition of the adsorbent beyond this concentration did not cause any significant change in the adsorption which may be due to the formation of clusters of

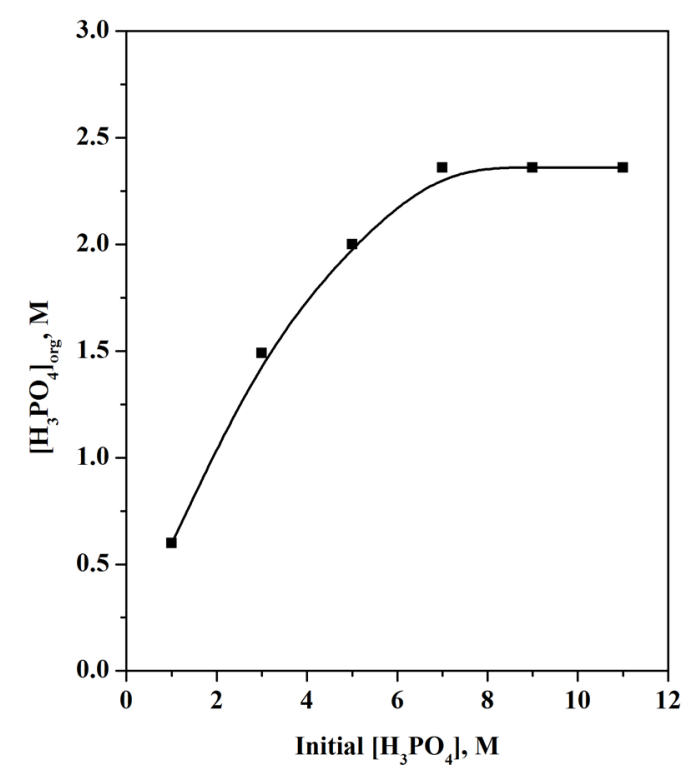

Fig. 3 Effect of initial phosphoric acid concentrations on its extraction by 1.18 M CYANEX 923 in kerosene at phase ratio (O/A) 2:1.

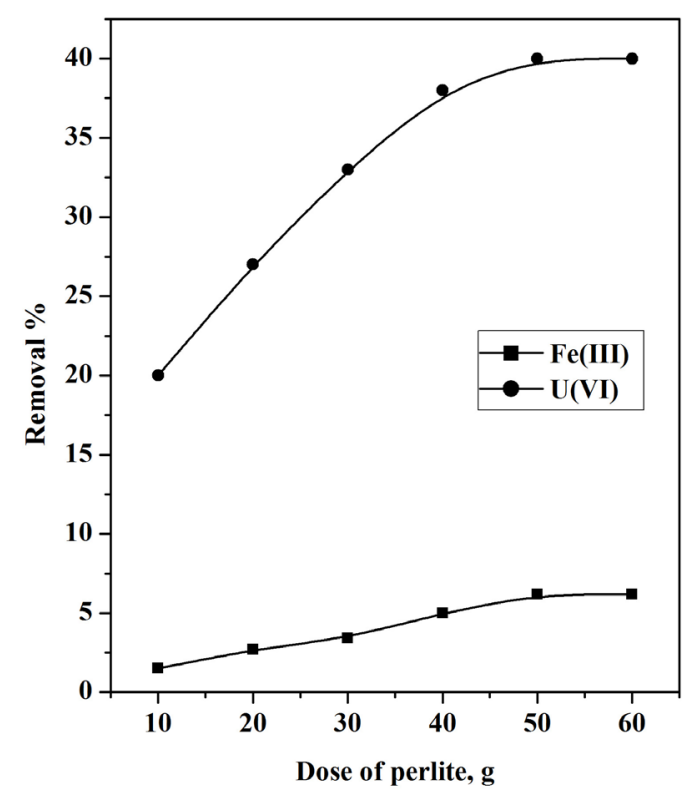

Fig. 4 Effect of perlite dose on the removal of Fe(III) and U(VI) from crude phosphoric acid. $[\mathrm{Fe}(\mathrm{III})]=16 \times 10^{3} \mathrm{ppm}[\mathrm{U}(\mathrm{VI})]=112 \mathrm{ppm}$ 
adsorbent particles leading to a decrease in the surface area. These results are parallel with studies carried out with natural zeolite, quartz and white silica sand [26-28].

The preference of an adsorbent for a metal may be explained on the basis of the electronegativity of the metal ions and ionic radius. Higher adsorption of iron could be related to its higher electronegativity and smaller ionic radius [28].

At higher phosphoric acid concentration (4.3-6.6 $\mathrm{M}$ or higher) in WPA, uranium exists as $\mathrm{UO}_{2}\left(\mathrm{H}_{2} \mathrm{PO}_{4}\right)_{2}$ [29] which refers to the interaction between the above species and perlite surface through silanol groups, $\mathrm{Si}-\mathrm{OH}$.

\subsubsection{Adsorption isotherm}

Experiments were conducted to study the effect of varying the initial metal ions concentration on the removal of Fe(III) and U(VI) from wet phosphoric acid by expanded perlite as an adsorbent, when keeping the other parameters constant. The experiments were done using $50 \mathrm{~g} / \mathrm{L}$ adsorbent with different metal ion concentrations ranging from $2-16 \times 10^{3}$ and $10-112 \mathrm{ppm}$ for Fe(III) and U(VI), respectively at $25^{\circ} \mathrm{C}$. Fig. 5 a, b shows that the uptake increased with increasing the initial metals concentration. This can be explained from the point that at high concentrations, the number of metal ions was relatively high compared with the available adsorption sites. The difference in the affinity of Fe(III) and U(VI) towards the removal on expanded perlite may be attributed to the difference in their chemical affinities and ion exchange capacities with respect to the

a)

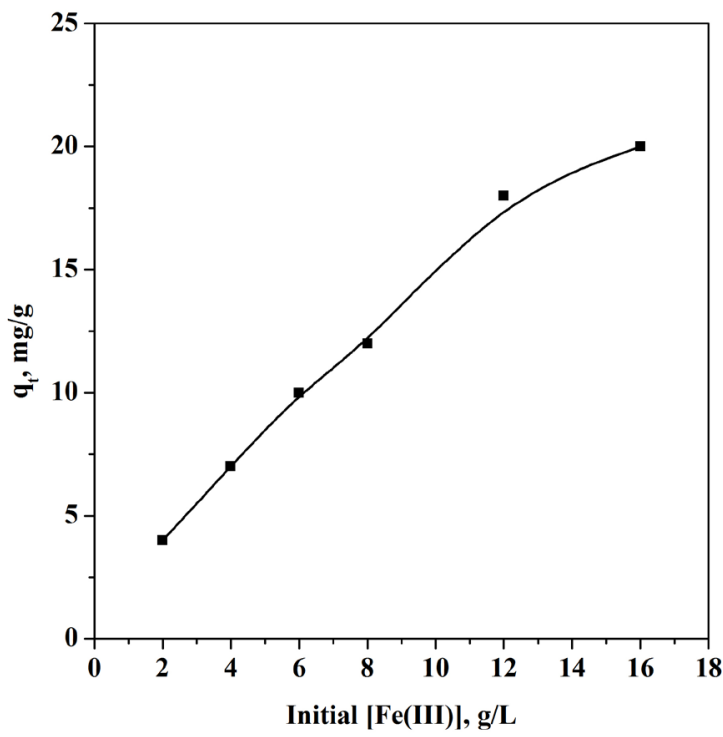

adsorbent. The maximum adsorption for Fe(III) and U(VI) was found to be 20.0 and $0.9 \mathrm{mg} / \mathrm{g}$, respectively.

\subsubsection{Removal of fluoride, uranium and iron by perlite from crude phosphoric acid}

The use of perlite decreased the concentration of fluoride from $950 \mathrm{ppm}$ to $25 \mathrm{ppm}$, i.e the removal reached $97.4 \%$; the concentration of uranium decreased from 112 to $67 \mathrm{ppm}$ with removal of $40.2 \%$, whereas the iron decreased from 16.0 to $15.0 \mathrm{~g} / \mathrm{L}$ with removal of $6.6 \%$. The obtained results show the role of perlite in minimizing the content of uranium and iron.

It has to be mentioned that no significant sorption of phosphoric acid on perlite was observed.

\subsection{Extraction of phosphoric acid from treated crude acid}

The treated phosphoric acid solution was shaken with 1.18 M CYANEX 923 in kerosene at phase ratio $\mathrm{O} / \mathrm{A}=2$ for $15 \mathrm{~min}$. The results show that the extraction percent of $\mathrm{P}_{2} \mathrm{O}_{5}, \mathrm{Fe}, \mathrm{F}$ and $\mathrm{U}$ were $82.6,2.5$, Nil and $66 \%$, respectively after 3 extraction stages. CYANEX 923 shows the advantage of high extraction of $\mathrm{P}_{2} \mathrm{O}_{5}$ and uranium and very poor extraction towards $\mathrm{Fe}$ (III) and fluoride from high acid concentration, which indicates that this extractant is superior over other organophosphorus extractants (phosphonic, phosphinic and thio phosphinic acid extractants) that show a high co-extraction of $\mathrm{Fe}$ (III) with $\mathrm{P}_{2} \mathrm{O}_{5}$. The loaded $\mathrm{P}_{2} \mathrm{O}_{5}$ was stripped with distilled water; the stripping percent

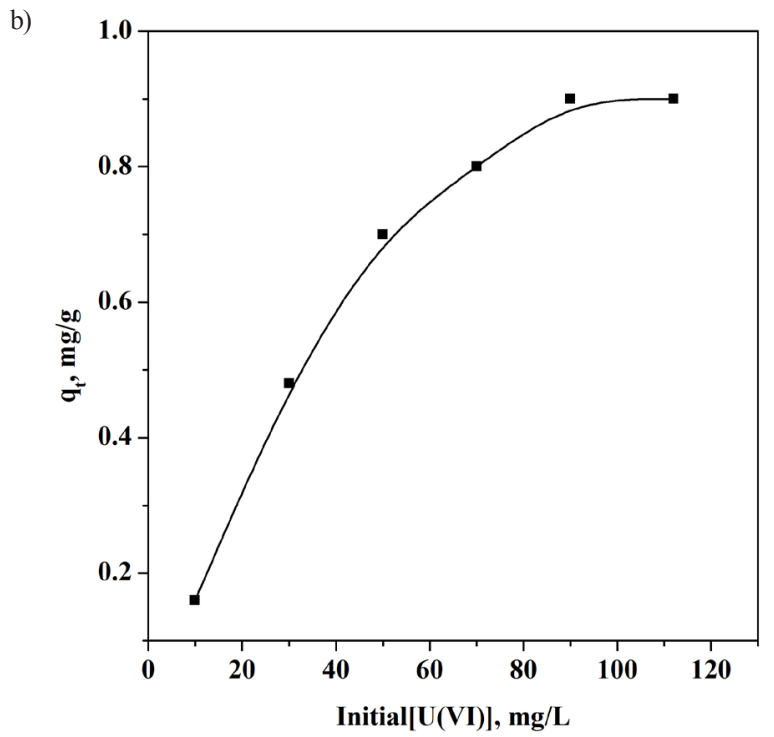

Fig. 5 a) Equilibrium adsorption isotherms for Fe(III) removal from crude phosphoric acid by Perlite. b) Equilibrium adsorption isotherms for U(VI) removal from crude phosphoric acid by Perlite. 
reached $94 \%$ after one stage then uranium was efficiently stripped with $2.0 \mathrm{M} \mathrm{Na}_{2} \mathrm{CO}_{3}$ solution, where a stripping percent of $90 \%$ was obtained after one stage. The analysis of the purified phosphoric acid indicates that it is composed of $\mathrm{P}_{2} \mathrm{O}_{5}, \mathrm{Fe}, \mathrm{F}$ and $\mathrm{U}$ of concentration $43.9 \%$, $400 \mathrm{ppm}$, nil and nil, respectively The extraction of U(VI) by different organic extractants from crude phosphoric acid is given in Table 4.

\subsection{Extraction of phosphoric acid from leached apatite ore}

As mentioned before in the experimental section, $25.0 \mathrm{~g}$ of apatite ore of particle size $150 \mu \mathrm{m}$ was agitated with $100 \mathrm{~mL}$ of $20 \% \mathrm{HCl}$ for $2 \mathrm{hrs}$. at mixing speed $400 \mathrm{rpm}$ and room temperature. After filtration, the obtained acidified solution was analyzed and the results obtained show that the concentrations of $\mathrm{P}_{2} \mathrm{O}_{5}, \mathrm{Fe}, \mathrm{F}$ was $75.0,6.0,2.5 \mathrm{~g} / \mathrm{L}$, respectively, while the concentration of uranium was found to be $12 \mathrm{ppm}$. The acidified solution was deflourinated by adding $2.0 \mathrm{~g}$ of sodium chloride then agitated for $2.0 \mathrm{hrs}$; the filtered solution was treated with $5.0 \mathrm{~g}$ perlite for $3.0 \mathrm{hrs}$. It was found that fluoride and uranium were completely removed.

The acidified solution was shaken with 1.18 M CYANEX 923 in kerosene at phase ratio $\mathrm{O} / \mathrm{A}=2 / 1$ for $15 \mathrm{~min}$. The results show that the extraction percent of $\mathrm{P}_{2} \mathrm{O}_{5}$ and $\mathrm{Fe}$ was 90 and $70 \%$, respectively. The co-extraction of iron may be related to the formation of $\mathrm{FeCl}_{3}$ and $\mathrm{FeCl}_{4}{ }^{-}$species that are readily extracted by organophosphorus extractants and the salting- out effect by chloride ion [35] that show high co-extraction of iron (III) with $\mathrm{P}_{2} \mathrm{O}_{5}$.
A flow diagram for the recovery of phosphoric acid from the crude acid and leached apatite ore is proposed, Fig. 6.

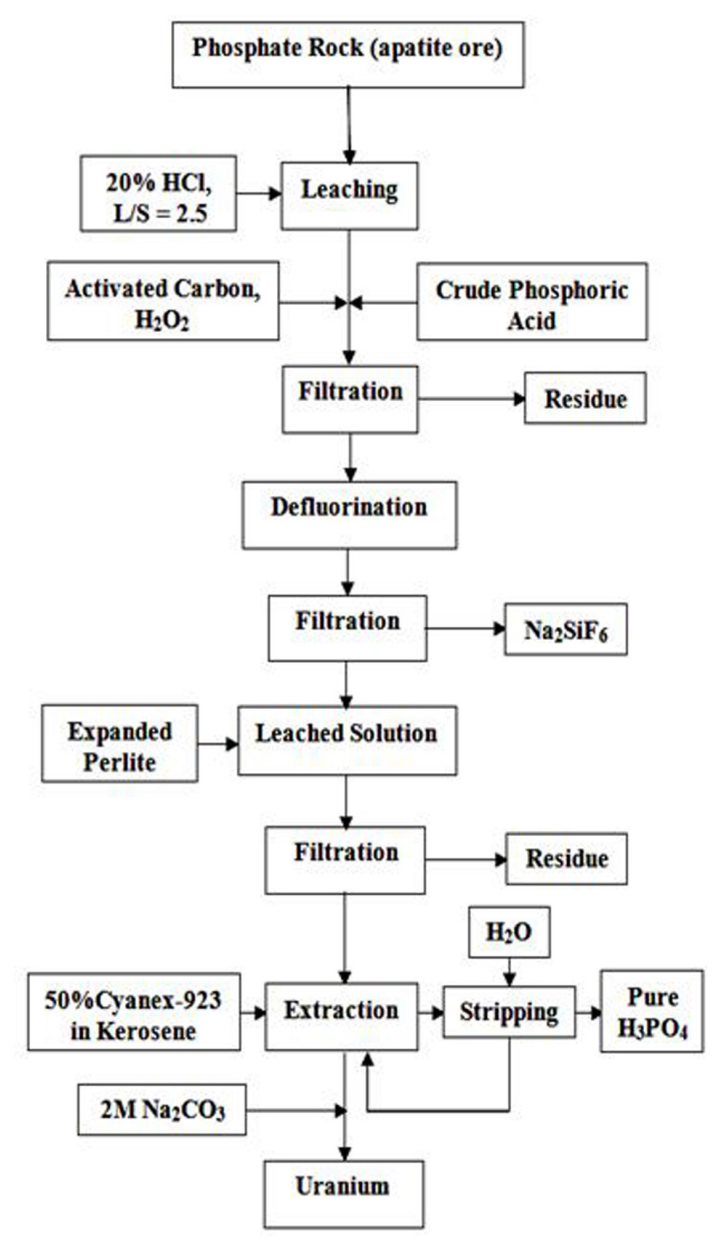

Fig. 6 Flow Chart of the recovery of phosphoric acid and uranium from apatite ore and crude phosphoric acid

Table 4 The extraction of U(VI) by different organophosphorus extractants from crude phosphoric acid.

\begin{tabular}{|c|c|c|c|c|}
\hline [Extractant], & {$\left[\mathrm{P}_{2} \mathrm{O}_{5}\right], \%$} & {$[\mathrm{U}], \mathrm{ppm}$} & $\mathrm{D}_{\mathrm{u}}$ & Ref. \\
\hline $\begin{array}{l}0.1 \mathrm{M} ; \mathrm{O} / \mathrm{A}=1 \\
0.1 \mathrm{M}-\mathrm{PN}-1200\end{array}$ & 29 & 83 & 8.2 & {$[30]$} \\
\hline $0.2 \mathrm{M} \mathrm{D}_{2} \mathrm{EHPA}+0.05 \mathrm{M}$ TOPO & 29 & 83 & 5.5 & {$[30]$} \\
\hline $0.7 \mathrm{M} \mathrm{D}_{2} \mathrm{EHPA}$ & 31.5 & 205 & 21.3 & {$[29]$} \\
\hline $0.38 \mathrm{M}$ ТОРО & 31.5 & 205 & 4.4 & {$[29]$} \\
\hline $1.0 \mathrm{MD}_{2} \mathrm{EHPA}+0.25 \mathrm{M}$ TOPO & 31.5 & 205 & 2.7 & {$[29]$} \\
\hline $0.5 \mathrm{MD}_{2} \mathrm{EHPA}+0.0125 \mathrm{M}$ ТОРО & 28 & 71 & 10 & {$[31]$} \\
\hline 0.15 M PC88A+0.15 M Cyanex 923 & 21.5 & 312 & 0.65 & {$[32]$} \\
\hline $0.6 \mathrm{MNPPA}+0.3 \mathrm{MTBP}$ & 44 & 62 & 4.17 & {$[33]$} \\
\hline $0.5 \mathrm{M} \mathrm{D}_{2} \mathrm{EHPA}$ & 30 & 144 & 11.8 & {$[34]$} \\
\hline 0.125 M DiBOPP & 30 & 144 & 354 & {$[34]$} \\
\hline 1.18 M Cyanex 923, O/A = 2 & 56.5 & 112 & 0.92 & Present work \\
\hline
\end{tabular}

PN-1200: polyalkyl phosphazenes; $\mathrm{D}_{2}$ EHPA: Di-(2-ethylhexyl)phosphoric acid; TOPO: Trioctylphosphine oxide; TBP: Tributyl phosphate; DiBOPP: (1,3-dialkyloxypropan-2-yl) phosphoric acids 


\section{Conclusions}

- Deflourination of crude phosphoric acid was carried out by adding sodium chloride to remove fluoride as sodium fluorosilicate.

- Perlite was used as an adsorbent for Fe(III) and U(VI) from crude phosphoric acid and the capacity of $\mathrm{Fe}(\mathrm{III})$ and $\mathrm{U}(\mathrm{VI})$ was found to be 20 and $0.9 \mathrm{mg} / \mathrm{g}$, respectively.

- Phosphoric acid was efficiently extracted by CYANEX 923 in kerosene with little contamination of $\mathrm{Fe}(\mathrm{III})$ and U(VI). The process was applied for the recovery of phosphoric acid from the crude acid.

- Apatite ore was leached with $20 \% \mathrm{HCl}$ solution at L/S

\section{References}

[1] Li, X., Li, J., Jin, Y., Chen, M., Feng, D., Guo, Y. "Wet process of phosphoric acid purification by solvent extraction using tri-n-butyl phosphate and cyclohexanol mixtures", Journal of the Serbian Chemical Society, 82, pp. 1-14, 2017. https://doi.org/10.2298/JSC161028019L

[2] Amin, M. I., Ali, M. M., Kamal, H. M., Youssef, A. M. Akl, M. A. "Recovery of high grade phosphoric acid from wet process acid by solvent extraction with aliphatic alcohols", Hydrometallurgy, 105(1-2), pp. 115-119, 2010.

https://doi.org/10.1016/j.hydromet.2010.08.007

[3] Jia, X., Li, J., Jin, Y., Luo, J., Wang, B., Qi, Y. "Liquid-liquid equilibrium in the nitric acid/phosphoric acid/water/tri-n-octylamine system", Journal of Chemical \& Engineering Data, 58, pp. 78-83, 2013.

https://doi.org/10.1021/je300917b

[4] Hamdi, R., Khleifia, N., Tlili, N., Hannachi, A. "Prediction of the concentration profiles along a continuous liquid-liquid extraction column for phosphoric acid purification." In: The First International Chemical and Process Engineering, Tripoli, 2009.

[5] Hannachi, A., Habaili, D., Chtara, C., Ratel, A. "Purification of wet process phosphoric acid by solvent extraction with TBP and MIBK mixtures." Separation and Purification Technology, 55(2), pp. 212-216, 2007.

https://doi.org/10.1016/j.seppur.2006.12.014

[6] Khleifia, N., Hamdi, R., Hannachi, A. "Etude de l'extraction de l'acide phosphorique industriel dans une columne Continue", (Study the extraxtion of industrial phosphoric aciid by a continuous column.) In: Proceedings of the 7th J.T.E.T, Tunisia, 2010. (in French)

[7] Awwad, N. S., El-Nadi, Y. A., Hamed, M. H. "Successive processes for purification and extraction of phosphoric acid produced by wet process", Chemical Engineering and Processing, 74, pp. 69-74, 2013.

https://doi.org/10.1016/j.cep.2012.11.009

[8] Chen, H., Sun, Z., Song, X., Yu, J. "Efficient Extraction of Phosphoric Acid with a Trialkyl Amine-Based Solvent Mixture", Journal of Chemical \& Engineering Data, 61(1), pp. 438-443, 2016. https://doi.org/10.1021/acs.jced.5b00626 ratio of 2.5 for $2 \mathrm{hrs}$ at room temperature, the resulting acidified solution was treated with sodium chloride and perlite to remove the fluoride and uranium.

- Co-extraction of Fe with $\mathrm{P}_{2} \mathrm{O}_{5}$ was observed during the extraction with CYANEX923 from apatite leached with $\mathrm{HCl}$, due to the salting-out effect of the chloride ions present in the chloride medium.

- After extraction of uranium and removal of fluoride and organic matter, almost pure phosphoric acid solution which meets the limiting values of the higher grade acid can be obtained after extraction using CYANEX 923 from crude phosphoric acid.

[9] Ma, Y., Zhou, W., Zhou, J. "Effects of impurity ions on the metastable zone width of phosphoric acid in tributyl phosphate", Journal of Chemical \& Engineering Data, 59, pp. 2909-2913, 2014. https://doi.org/10.1021/je500554c

[10] Zhong, B., Li, J., Guo, X., Wu, D. "Current research status and development direction of purification technology of wet-process phosphoric acid", Inorganic Chemical Industry, 40, pp. 9-12, 2008. https://doi.org/10.3969/j.issn.1006-4990.2008.02.003

[11] Liu, C., Ren, Y., Tian, D., Zhang, X., Wang, Y., Kong, L., Shen, W. "Equilibria of the quaternary system including phosphoric acid hydrochloric acid, water and tri-n-butyl phosphate at $\mathrm{T}=303.2 \mathrm{~K}$ and atmosphere pressure", Journal of Chemical Thermodynamics, 79, pp. 118-123, 2014. https://doi.org/10.1016/j.jct.2014.08.003

[12] Alibrahim, M. "Extraction of phosphoric acid from various aqueous solutions using tributylphosphate (TBP)", Periodica Polytechnica Chemical Engineering, 51(1), pp. 39-42, 2007. https://doi.org/10.3311/pp.ch.2007-1.07

[13] Sanghani, R. "Novel Technique for Purification of Fertilizer Phosphoric acid with Simultaneous Uranium Extraction", Procedia Engineering, 83, pp. 225-232, 2014. https://doi.org/10.1016/j.proeng.2014.09.042

[14] El-Asmy, A. A., Serag, H. M., Mahdy, M. A., Amin, M. I. "Purification of phosphoric acid by minimizing iron, copper, cadmium and fluoride", Separation and Purification Technology, 61, pp. 287-292, 2008 https://doi.org/10.1016/j.seppur.2007.11.004

[15] Ennaassia, Et., El Kacemi, K., Kossir, A., Cote, G. "Study of the removal of $\mathrm{Cd}(\mathrm{II})$ from phosphoric acid solutions by precipitation of CdS with $\mathrm{Na}_{2} \mathrm{~S}$ ", Hydrometallurgy, 64(2), pp. 101-109, 2002. https://doi.org/10.1016/S0304-386X(02)00009-9

[16] El-Nadi, Y. A., Daoud, J. A. "Sulphide precipitation of iron and its effect on the extraction of uranium from phosphoric acid medium", Journal of Nuclear and Radiochemical Sciences, 5(1), pp. 11-15, 2004. https://oi.org/10.14494/jnrs2000.5.11

[17] Abdulbaki, M. A. "Removal of fluoride from commercial Syrian wet phosphoric acid by precipitation", Indian Journal Chemical Technology, 14(4), pp. 430-431, 2007. 
[18] El-Bayaa, A. A., Badawy, N. A., Gamal, A. M., Zidan, I. H., Mowafy, A. R. "Purification of wet process phosphoric acid by decreasing iron and uranium using white silica sand", Journal of Hazardous Materials, 190, pp. 324-329, 2011. https://doi.org/10.1016/j.jhazmat.2011.03.037

[19] Chehid Elleuch, M. B., Amor, M. B., Pourcelly, G. "Phosphoric acid purification by a membrane process: electrodeionization on ion-exchange textiles", Separation and Purification Technology, 51, pp. 285-290, 2006.

https://doi.org/10.1016/j.seppur.2006.02.009

[20] Gonzalez, M. P., Navarro, R., Saucedo, I., Avila, M., Revilla, J., Bouchard, C. "Purification of phosphoric acid solutions by reverse osmosis and nanofiltration", Desalination, 147, pp. 315-320, 2002. https://doi.org/10.1016/S0011-9164(02)00558-1

[21] Jordan, D. "Determination of total fluoride and/or fluosilicic acid concentration by specific fluoride ion electrode potentiometry", Journal - Association of Official Analytical Chemists, 53(3), pp. $447-450,1970$.

[22] Ghanadzadeh Gilani, H., Ghanadzadeh Gilani, A., Shekarsaraee, S. "Solubility and tie line data of the water-phosphoric acid-solvents at $\mathrm{T}=303.2,313.2$, and $323.2 \mathrm{~K}$ : An experimental and correlational study", Thermochimica Acta, 558, pp. 36-45, 2013. https://doi.org/10.1016/j.tca.2013.02.006

[23] Nayl, A. "Studies on the extraction and purification of phosphoric acid and certain lanthanides of nuclear interest." PhD Theses, Ain shams University, Egypt, 2004.

[24] Campos Assuncao, M., Cote, G., Andre, M., Halleux H., Chagnes, A. "Phosphoric acid recovery from concentrated aqueous feeds by a mixture of di-isopropyl ether (DiPE) and tri-n-butylphosphate (TBP): extraction data and modelling", Royal Society of Chemistry Advances, 7, pp. 6922-6930, 2017. https://doi.org/10.1039/C6RA25440C

[25] Mathialagan, T., Viraraghavan, T. "Adsorption of cadmium from aqueous solutions by perlite", Journal of Hazardous Materials, B94, pp. 291-303, 2002. https://doi.org/10.1016/S0304-3894(02)00084-5

[26] Al-Anber, M. A. "Removal of high-level $\mathrm{Fe}^{3+}$ from aqueous solution using natural inorganic materials: bentonite (NB) and quartz (NQ)", Desalination, 250, pp. 885-891, 2010. https://doi.org/10.1016/j.desal.2009.06.071

[27] Al-Anber, M. A., Al-Anber, Z. A. "Utilization of natural zeolite as ion-exchange and sorbent material in the removal of iron", Desalination, 255, pp. 70-81, 2008. https://doi.org/10.1016/j.desal.2007.07.006
[28] El-Bayaa, A. A., Badawy, N. A., Gamal, A. M., Zidan, I. H., Mowafy, A. R. "Purification of wet processphosphoric acid by decreasing iron and uranium using white silica sand", Journal of Hazardous Material, 190, pp. 324-329, 2011. https://doi.org/10.1016/j.jhazmat.2011.03.037

[29] Girgin, S., Acarkan, N., Ali Sirkeci, A. "The uranium(VI) extraction mechanism of D2EHPA-TOPO from a wet process phosphoric acid", Journal of Radioanalytical and Nuclear Chemistry, 251(2), pp. 263-271, 2002. https://doi.org/10.1023/A:1014816310718

[30] Nazari, K., Ghannadi Maragheh, M., Jabbari Rad, A. "Studies on extraction of uranium from phosphoric acid using PN-1200 extractant", Hydrometallurgy, 71, pp. 371-377, 2004 https://doi.org/10.1016/S0304-386X(03)00088-4

[31] Rawajfeh, K. M., Al-Matar, A. Kh. "Uranium extraction from purified wet process Jordanian phosphoric acid: a development study", Hydrometallurgy, 56, pp. 309-322, 2000. https://doi.org/10.1016/S0304-386X(00)00080-3

[32] Singh, S. K., Misra, S. K., Tripathi, S. C., Singh, D. K. "Studies on permeation of uranium (VI) from phosphoric acid medium through supported liquid membrane comprising a binary mixture of PC88A and Cyanex 923 in n-dodecane as carrier", Desalination, 250, pp. 19-25, 2010. https://doi.org/10.1016/j.desal.2009.06.067

[33] Abdel- Magied, A. F., Amin, M. I. "Uranium(VI) extraction from concentrated Egyptian wet-process phosphoric acid using a synergistic organophosphorous solvent mixture", International Journal of Industrial Chemistry, 7, pp. 21-28, 2016. https://doi.org/10.1007/s40090-015-0056-6

[34] Beltrami, D., Chagnes, A., Haddad, M., Varnek, A., Mokhtari, H., Courtaud, B., Cote, G. "Recovery of uranium (VI) from concentrated phosphoric acid by mixtures of new bis (1,3-dialkyloxypropan-2-yl) phosphoric acids and tri-n-octylphosphine oxide", Hydrometallurgy, 140, pp. 28-33, 2013. https://doi.org/10.1016/j.hydromet.2013.08.008

[35] Ahmed, I. M. "Chemical studies on the extraction and separation of certain metal ions from aqueous waste solutions." $\mathrm{PhD}$ Theses, Ain shams University, Egypt, 2008. 